\title{
Panel Flutter Analysis and Optimization of Composite Tow Steered Plates
}

\author{
Thiago A. M. Guimarães * \\ *Federal University of Uberlândia, Uberlândia, MG, 38408-100, Brazil \\ Saullo G. P. Castro ${ }^{\dagger}$ \\ ${ }^{\dagger}$ Embraer, São José dos Campos, SP, 12217-901, Brazil \\ Domingos A. Rade $\ddagger$ \\ Technological Institute of Aeronautics, São José dos Campos, SP, 12228-900, Brazil \\ Carlos E. S. Cesnik $\S$ \\ University of Michigan, Ann Arbor, Michigan 48109-2140
}

\begin{abstract}
The flutter behavior of tow steered composite panels, in which the fiber placement follow curvilinear trajectory, is evaluated. A simple structural model based on Ritz method combined with supersonic aerodynamic piston theory is used to analyze the aeroelastic behavior. Classical lamination plate theory and symmetric stacking sequence are used and the fiber trajectories are defined by Lagrange interpolation functions. The flutter stability boundaries for optimal conventional (constant stiffness laminates) layups and nonconventional (variable stiffness laminates) steered panels are numerically compared. The effect of in-plane loads is also accounted for in the aeroelastic analyses.
\end{abstract}

\section{Introduction}

The panel flutter phenomenon is caused by the interaction of inertial, elastic and aerodynamic forces generated by supersonic airflow. The safe design is driven by the determination of critical aerodynamic conditions regarding Mach and dynamic pressure. Early studies were devoted to understanding the aeroelastic instability in V-2 rockets using different structural and aerodynamic modeling approaches. ${ }^{1}$

Dowell ${ }^{2}$ presents a review of panel flutter, introducing the theoretical mathematical analysis and correlations with experiments. Yang ${ }^{3}$ proposed a double curved thin shell finite element for modeling of composite plates, curved panels, and composite cylindrical shells. Mei and coworkers ${ }^{4}$ developed finite element models to evaluate nonlinear flutter of composite panels considering the von Kàrman large-deflection straindisplacement relations in the time domain. They also evaluated the nonlinear behavior of composite panels for different configurations regarding aspect ratios, lamination angles and number of layers. ${ }^{5}$ Afterwards, different approaches were developed to improve design and to control instabilities, such as active control by using piezoelectric actuators, ${ }^{6}$ considering the stiffener's base as structural elements ${ }^{7}$ and using electrorheological fluids. ${ }^{8}$

The classic strategy of aeroelastic tailoring consists in stacking plies in different orientations for aeroelastic benefits. This design technique has been employed in different projects, such as the flight demonstrator X29, in which the problem of low divergence speed was solved by arranging the stacking sequence to explore the terms of bending-torsion coupling in its composite wing. ${ }^{9}$

${ }^{*}$ Ph.D. Research Student, Federal University of Uberlândia, Department of Mechanical Engineering, Av. João Naves de Ávila 2121, and Student Member AIAA

${ }^{\dagger} \mathrm{PhD}$ in Structural Modeling and Product Development Engineer, EMBRAER, Av. Brigadeiro Faria Lima 2170

¥Professor, Technological Institute of Aeronautics, Praça Mal. Eduardo Gomes 50, Vila das Acácias, Associate Fellow AIAA

$\S$ Professor of Aerospace Engineering, Department of Aerospace Engineering, 1320 Beal Avenue. Fellow AIAA 
The improvement of fiber placement techniques and the use of automated procedures culminated with the emergence and development of new manufacturing processes. The automated fiber placement (AFP) process enables to manufacture variable stiffness panels (VSP), allowing increased design flexibility and new possibilities to enhance the composite laminate structural design. Examples of VSP can be found to improve buckling, ${ }^{10}$ to reduce stress concentrations around holes, ${ }^{11}$ to maximize the fundamental frequency ${ }^{12}$ and to optimize aeroelastic characteristics of composite wing ${ }^{13} \cdot{ }^{14}$

The impact of defects in variable stiffness plates, especially gaps and overlaps, was neglected in the literature until the recent years. ${ }^{15}$ The "Defect layer" method highlights the effect of defects in the critical buckling load and in-plane stiffness. ${ }^{16}$ The most common approach to manufacture variable stiffness plates consists in defining the tow steering angle as functions of two values in the edges of the plate $\left(T_{0}\right.$ and $\left.T_{1}\right)$, due to the advantage to easily control the turning radius from these parameters. The defects are dependent mainly on the turning radius, whose the minimum value depends on the fiber width. ${ }^{17}$

The high cost of optimizing VSP (steered laminates) is a consequence of the large number of design variables required to define the trajectory, thicknesses and manufacturing constraints. ${ }^{18}$ This is in contrast with the traditional composite laminated structures (unsteered laminates) that involve the task of finding a combination of several straight-fibers layers with constant thicknesses, aiming the best mechanical properties for different design purposes. ${ }^{19}$

This paper proposes a new evaluation approach for panel flutter by using aeroelastic tailoring of tow steered composite laminates. The flutter analysis results for several configurations (steered and unsteered) are optimized and compared. A differential evolution (DE) algorithm is applied to optimize the tow steered composite plates providing promising results. For the optimized solutions, the instability boundaries are evaluated considering in-plane loads and a multi-objective optimization with manufacturing constraints. The plate is modeled according to the Classical Lamination Theory (CLT), whereas sinusoidal functions are used as basis for the Ritz Method. The fiber placement trajectory is specified by controlling points interpolated by Lagrange polynomials of different orders. ${ }^{18}$ The aerodynamic model is based on the potential flow theory combined with high Mach number approximation.

\section{Formulation}

\section{A. Structural Model}

The plate is modeled based on von-Krman strain-displacement assumptions, according to the Classical Lamination Theory and each ply is assumed to be in plane strain, which means that all the out-of-plane strains are set to zero:

$$
\gamma_{z x}=\gamma_{z y}=\epsilon_{z z}=0
$$

The displacement field is represented as:

$$
\begin{aligned}
& u(x, y, z, t)=u_{0}(x, y, t)-z \frac{\partial w_{0}(x, y, t)}{\partial x} \\
& v(x, y, z, t)=v_{0}(x, y, t)-z \frac{\partial w_{0}(x, y, t)}{\partial y} \\
& w(x, y, z, t)=w_{0}(x, y, t)
\end{aligned}
$$

where $\left(u_{0}, v_{0}, w_{0}\right)$ are the displacements in the midplane.

Assuming small strains and moderately large rotations, the strain components are expressed as:

$$
\epsilon=\left\{\begin{array}{c}
\epsilon_{x} \\
\epsilon_{y} \\
\gamma_{x y}
\end{array}\right\}=\left\{\begin{array}{c}
\frac{\partial u_{0}(x, y, t)}{\partial x}-z \frac{\partial^{2} w_{0}(x, y, t)}{\partial x^{2}}+\frac{1}{2}\left(\frac{\partial w_{0}(x, y, t)}{\partial x}\right)^{2} \\
\frac{\partial v_{0}(x, y, t)}{\partial y}-z \frac{\partial^{2} w_{0}(x, y, t)}{\partial y^{2}}+\frac{1}{2}\left(\frac{\partial w_{0}(x, y, t)}{\partial y}\right)^{2} \\
\frac{\partial u_{0}(x, y, t)}{\partial x}+\frac{\partial v_{0}(x, y, t)}{\partial y}-2 z \frac{\partial^{2} w_{0}(x, y, t)}{\partial y \partial x}+\frac{\partial w_{0}(x, y, t)}{\partial x} \frac{\partial w_{0}(x, y, t)}{\partial y}
\end{array}\right\}
$$

where the linear and nonlinear terms are denoted as:

$$
\epsilon^{\mathbf{L}}=\left\{\begin{array}{c}
\epsilon_{x}^{L} \\
\epsilon_{y}^{L} \\
\gamma_{x y}^{L}
\end{array}\right\}=\left\{\begin{array}{c}
\frac{\partial u_{0}(x, y, t)}{\partial x} \\
\frac{\partial v_{0}(x, y, t)}{\partial y} \\
\frac{\partial u_{0}(x, y, t)}{\partial x}+\frac{\partial v_{0}(x, y, t)}{\partial y}
\end{array}\right\}
$$




$$
\begin{gathered}
\kappa=\left\{\begin{array}{c}
\kappa_{x} \\
\kappa_{y} \\
\kappa_{x y}
\end{array}\right\}=-\left\{\begin{array}{c}
\frac{\partial^{2} w_{0}(x, y, t)}{\partial x^{2}} \\
\frac{\partial^{2} w_{0}(x, y, t)}{\partial y^{2}} \\
2 \frac{\partial^{2} w_{0}(x, y, t)}{\partial x \partial y}
\end{array}\right\} \\
\epsilon^{\mathbf{N L}}=\left\{\begin{array}{c}
\epsilon_{x}^{N L} \\
\epsilon_{y}^{N L} \\
\gamma_{x y}^{N L}
\end{array}\right\}=\left\{\begin{array}{c}
\frac{1}{2}\left(\frac{\partial w_{0}(x, y, t)}{\partial x}\right)^{2} \\
\frac{1}{2}\left(\frac{\partial w_{0}(x, y, t)}{\partial y}\right)^{2} \\
\frac{\partial w_{0}(x, y, t)}{\partial x} \frac{\partial w_{0}(x, y, t)}{\partial y}
\end{array}\right\}
\end{gathered}
$$

Then, the forces (Q) and moments (B), with the assumptions of CLT, are:

$$
\left\{\begin{array}{l}
\mathbf{Q} \\
\mathbf{B}
\end{array}\right\}=\left[\begin{array}{cc}
\mathbf{A} & \mathbf{B} \\
\mathbf{B}^{T} & \mathbf{D}
\end{array}\right]\left\{\begin{array}{c}
\epsilon^{\mathbf{L}}+\epsilon^{\mathbf{N L}} \\
\kappa
\end{array}\right\}
$$

in which, the membrane, membrane-bending and bending terms are given by the matrices $\boldsymbol{A}, \boldsymbol{B}$ and $\boldsymbol{D}$. In the case of VSP plates, these matrices must be computed accounting for the fact that the fiber angle varies over the ply according to Lagrange polynomials: ${ }^{18}$

$$
\theta(x, y)=\Phi_{i}+\sum_{m=0}^{M-1} \sum_{n=0}^{N-1} T_{m n} \cdot \prod_{m \neq i} \frac{x-x_{i}}{x_{m}-x_{i}} \cdot \prod_{n \neq j} \frac{y-y_{j}}{y_{n}-y_{j}}
$$

where $\Phi_{i}$ is the reference ply angle and $T_{m n}$ are the control angles in the reference points, as depicted in Fig. 1.

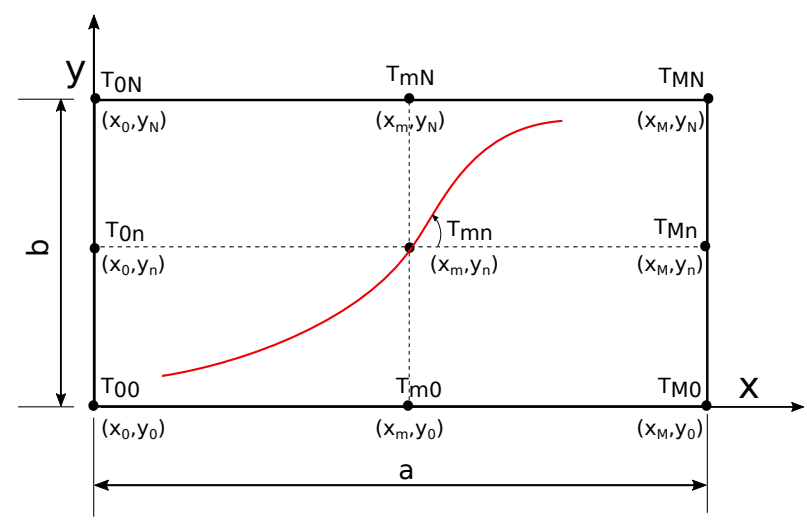

Figure 1. Non-linear fiber orientation by Lagrange polynomials. (Adapted from $\mathrm{Wu}^{18}$ )

Considering symmetric laminates $\boldsymbol{B}=\boldsymbol{O}$, the matrices $\boldsymbol{A}$ and $\boldsymbol{D}$ derived from a combination of in-plane and out-of-plane lamination parameters $\left(V_{i}\right.$ and $\left.W_{i}\right) .{ }^{20}$

$$
\begin{gathered}
\left(V_{1}, V_{2}, V_{3}, V_{4}\right)(x, y)=\frac{1}{h} \int_{-h / 2}^{h / 2}(\cos (2 \theta), \sin (2 \theta), \cos (4 \theta), \sin (4 \theta)) d z \\
\left(W_{1}, W_{2}, W_{3}, W_{4}\right)(x, y)=\frac{12}{h^{3}} \int_{-h / 2}^{h / 2} z^{2}(\cos (2 \theta), \sin (2 \theta), \cos (4 \theta), \sin (4 \theta)) d z
\end{gathered}
$$

and laminate invariants: ${ }^{21}$

$$
\begin{aligned}
\Gamma_{0}=\left[\begin{array}{ccc}
I_{1} & I_{4} & 0 \\
I_{4} & I_{1} & 0 \\
0 & 0 & I_{5}
\end{array}\right], \quad \Gamma_{1}=\left[\begin{array}{ccc}
I_{2} & 0 & 0 \\
0 & -I_{2} & 0 \\
0 & 0 & 0
\end{array}\right], \quad \Gamma_{2}=\left[\begin{array}{ccc}
0 & 0 & I_{2} / 2 \\
0 & 0 & I_{2} / 2 \\
I_{2} & I_{2} & 0
\end{array}\right], \\
\Gamma_{3}=\left[\begin{array}{ccc}
I_{3} & -I_{3} & 0 \\
-I_{3} & I_{3} & 0 \\
0 & 0 & -I_{3}
\end{array}\right], \quad \Gamma_{4}=\left[\begin{array}{ccc}
0 & 0 & I_{3} \\
0 & 0 & -I_{3} \\
I_{3} & -I_{3} & 0
\end{array}\right]
\end{aligned}
$$

$$
3 \text { of } 14
$$


are expressed as:

$$
\begin{aligned}
& {\left[\begin{array}{lll}
A_{11}(x, y) & A_{12}(x, y) & A_{16}(x, y) \\
A_{12}(x, y) & A_{22}(x, y) & A_{26}(x, y) \\
A_{16}(x, y) & A_{26}(x, y) & A_{66}(x, y)
\end{array}\right]=h\left(\Gamma_{0}+\Gamma_{1} V_{1}(x, y)+\Gamma_{2} V_{2}(x, y)+\Gamma_{3} V_{3}(x, y)+\Gamma_{4} V_{4}(x, y)\right)} \\
& {\left[\begin{array}{lll}
D_{11}(x, y) & D_{12}(x, y) & D_{16}(x, y) \\
D_{12}(x, y) & D_{22}(x, y) & D_{26}(x, y) \\
D_{16}(x, y) & D_{26}(x, y) & D_{66}(x, y)
\end{array}\right]=\frac{h^{3}}{12}\left(\Gamma_{0}+\Gamma_{1} W_{1}(x, y)+\Gamma_{2} W_{2}(x, y)+\Gamma_{3} W_{3}(x, y)+\Gamma_{4} W_{4}(x, y)\right)}
\end{aligned}
$$

where $h$ is the total thickness.

The strain energy of the composite plate may be expressed by:

$$
\begin{aligned}
U= & \frac{1}{2} \int_{0}^{a} \int_{0}^{b}\left\{\epsilon^{L}\right\}^{T}[\mathbf{A}]\left\{\epsilon^{L}\right\} d x d y+\frac{1}{2} \int_{0}^{a} \int_{0}^{b}\left\{\kappa^{L}\right\}^{T}[\mathbf{D}]\left\{\kappa^{L}\right\} d x d y+ \\
& \frac{1}{2} \int_{0}^{a} \int_{0}^{b}\left\{\epsilon^{N L}\right\}^{T}[\mathbf{A}]\left\{\epsilon^{L}\right\} d x d y+\frac{1}{2} \int_{0}^{a} \int_{0}^{b}\left\{\epsilon^{L}\right\}^{T}[\mathbf{A}]\left\{\epsilon^{N L}\right\} d x d y+ \\
& \frac{1}{2} \int_{0}^{a} \int_{0}^{b}\left\{\epsilon^{N L}\right\}^{T}[\mathbf{A}]\left\{\epsilon^{N L}\right\} d x d y \\
= & U_{1}+U_{2}+U_{3}+U_{4}+U_{5}
\end{aligned}
$$

For the complete solution for a fully simply supported plate, the transverse displacement field is approximated using:

$$
\begin{aligned}
& u_{0}(x, y, t)=\sum_{m=m_{0}}^{m_{\max }} \sum_{n=n_{0}}^{n_{\max }} p_{m n}(t) \sin \left(m \frac{x}{a}\right) \sin \left(n \frac{y}{b}\right) \\
& v_{0}(x, y, t)=\sum_{m=m_{0}}^{m_{\max }} \sum_{n=n_{0}}^{n_{\max }} q_{m n}(t) \sin \left(m \frac{x}{a}\right) \sin \left(n \frac{y}{b}\right) \\
& w_{0}(x, y, t)=\sum_{m=m_{0}}^{m_{\max }} \sum_{n=n_{0}}^{n_{\max }} r_{m n}(t) \sin \left(m \frac{x}{a}\right) \sin \left(n \frac{y}{b}\right)
\end{aligned}
$$

which can be rewritten in matrix notation as:

$$
\left\{\begin{array}{c}
u_{0}(x, y, t) \\
v_{0}(x, y, t) \\
w_{0}(x, y, t)
\end{array}\right\}=\left[\begin{array}{ccc}
\mathbf{S}_{u}^{T}(x, y) & 0 & 0 \\
0 & \mathbf{S}_{v}^{T}(x, y) & 0 \\
0 & 0 & \mathbf{S}_{w}^{T}(x, y)
\end{array}\right]\left\{\begin{array}{c}
\mathbf{q}_{\mathbf{u}} \\
\mathbf{q}_{\mathbf{v}} \\
\mathbf{q}_{\mathbf{w}}
\end{array}\right\}
$$

Based on the hypotheses of Kirchhoff theory, the kinetic energy $(\Upsilon)$, which is adequate for thin plates, writes: $^{22}$

$$
\Upsilon=\frac{1}{2} \iiint \rho_{0}\left[\dot{u}^{2}+\dot{v}^{2}+\dot{w}^{2}\right] d x d y d z
$$

where $\rho_{0}$ is the material density.

\section{B. Aerodynamic Model}

Based on potential flow assumptions, the aerodynamic pressure $\Delta P$ is modeled according to the method proposed by Amabili, ${ }^{23}$ known as third order piston theory:

$$
\Delta P=\frac{-p_{\infty}}{M_{a}}\left[\left(\frac{\partial w}{\partial x}+\frac{1}{U_{\infty}} \frac{\partial w}{\partial t}\right)+\frac{(1-\gamma) M_{a}}{4}\left(\frac{\partial w}{\partial x}+\frac{1}{U_{\infty}} \frac{\partial w}{\partial t}\right)^{2}+\frac{(1+\gamma) M_{a}^{2}}{12}\left(\frac{\partial w}{\partial x}+\frac{1}{U_{\infty}} \frac{\partial w}{\partial t}\right)^{3}\right]
$$

Then, the virtual work done by the aerodynamic load is expressed by:

$$
\delta W=\int_{0}^{a} \int_{0}^{b} \Delta P \delta w d x d y
$$




\section{Aeroelastic Model}

The aeroelastic model is obtained by combining the expressions of the strains energy (Eq. 14), kinetic energy (Eq 19), virtual work of the aerodynamic forces (Eq. 21), and the Lagrange's Equations. ${ }^{24}$

$$
\frac{d}{d t}\left(\frac{\partial T}{\partial \dot{\mathbf{q}}}\right)-\frac{\partial T}{\partial \mathbf{q}}+\frac{\partial U}{\partial \mathbf{q}}=\mathbf{Q}
$$

where, the generalized coordinates are $\mathbf{q}=\left[\begin{array}{lll}\mathbf{q}_{u}^{T} & \mathbf{q}_{v}^{T} & \mathbf{q}_{w}^{T}\end{array}\right]^{T}$.

Considering only linear terms and out-of-plane displacements, simplifying the aerodynamic loading to first order and neglecting aerodynamic damping, the equations of motions are obtained as:

$$
\mathbf{M} \ddot{\mathbf{q}}+(\lambda \mathbf{K}+\mathbf{C}) \mathbf{q}_{\mathbf{w}}=0,
$$

where $\mathbf{M}$ is the mass matrix, $\mathbf{K}$ is the aerodynamic stiffness matrix and $\mathbf{C}$ is the structural stiffness. Also, the parameter $\lambda$, which represents the airflow conditions, is conveniently defined as:

$$
\lambda=\frac{\rho_{\infty} U_{\infty}^{2}}{\sqrt{M_{\infty}^{2}-1}} .
$$

Thus, from solution of the following eigenvalue problem, the eigenvalues of the aeroelastic system can be evaluated. Flutter instabilities conditions are associated by inspections of the eigenvalues for different values of $\lambda$.

$$
\left(\lambda \mathbf{K}+\mathbf{C}-\omega^{2} \mathbf{M}\right) \mathbf{q}_{\mathbf{w}}=0
$$

\section{Linear Buckling}

Considering only prescribed in-plane loads, the associated potential Energy writes:

$$
V=-\frac{1}{2} \int_{0}^{a} \int_{0}^{b}\left[N x x\left(\frac{\partial w}{\partial x}\right)^{2}+N y y\left(\frac{\partial w}{\partial y}\right)^{2}+2 N x y \frac{\partial w}{\partial x} \frac{\partial w}{\partial y}\right] d x d y
$$

which results in the geometric stiffness matrix $\left(\mathbf{K}_{\mathbf{G}}\right)$. Then the general system of buckling equation is given as: ${ }^{25}$

$$
\left(\mathbf{K}-\Lambda \mathbf{K}_{\mathbf{G}}\right) \mathbf{q}_{\mathbf{w}}=0,
$$

where $(\mathbf{K})$ is the bending constitutive matrix.

The lowest eigenvalue associated with to Eq. 27 is the critical buckling load $\left(\Lambda_{\text {buck }}=\min (\Lambda)\right)$.

The full aeroelastic formulation including in plane loads, which is extensively treated in the literature to account for temperature effects, is also done herein considering only compressive loads in $\mathrm{x}$ direction (Nxx) conveniently expressed in function of the buckling load as:

$$
\alpha=\frac{N x x}{(N x x)_{b u c k}}
$$

being $(N x x)_{b u c k}$ equal to $\Lambda_{b u c k}$ when $\mathrm{Nxx}=1 ; \mathrm{Nyy}=0$ and $\mathrm{Nxy}=0$.

Consequently the combined problem of linear solution of aeroelastic and buckling is expressed as:

$$
\left(\lambda \mathbf{K}+\alpha \mathbf{K}_{\mathbf{G}}+\mathbf{C}-\omega^{2} \mathbf{M}\right) \mathbf{q}_{\mathbf{w}}=0
$$

\section{Test-case Description and model Verification}

Before analyzing the panel flutter of a tow steering laminate, first the lamina properties and plate geometry. Then, the numerical model is verified by comparing the natural frequencies and modes shapes, from the Rayleigh Ritz approach with the Nastran ${ }^{\circledR}$ model.

\section{A. Test-case Description}

Fig. 2 and Table 1 show a simply-supported plate dimensions and lamina properties. 


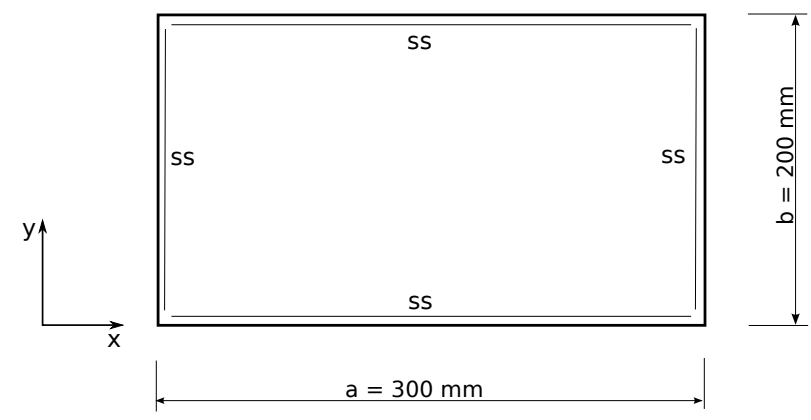

Figure 2. Plate Model Description

Table 1. Lamina Material properties and plate dimensions

\begin{tabular}{llll}
\hline Property & Value & Property & Value \\
\hline \hline$E_{1}$ & $129500 \mathrm{MPa}$ & Length, a & $400 \mathrm{~mm}$ \\
$E_{2}$ & $9370 \mathrm{MPa}$ & Width,b & $300 \mathrm{~mm}$ \\
$G_{12}$ & $5240 \mathrm{MPa}$ & Density, $\rho_{0}$ & $1500 \mathrm{~kg} / \mathrm{m}^{3}$ \\
$\mu_{12}$ & 0.38 & Ply thickness, t & $0.19 \mathrm{~mm}$ \\
\hline
\end{tabular}

\section{B. Model Verification}

In this section the model verification regarding natural frequencies and mode shapes is presented for two different plate configurations. Configuration A represents a common laminate with constant stiffness, and Configuration B is a variable stiffness plate.

For configuration A the stacking sequence of the four layers has been defined as $\left[0^{\circ} / 45^{\circ} /-45^{\circ} / 90^{\circ}\right]_{s}$ with dimensions and material properties as detailed in Table 1. For configuration B fiber deposition course is defined following the second order Lagrange polynomials, as definded in Eq. 8. It should be noted thats the same stacking sequence is adopted for configuration $\mathrm{B}$, in which the steered laminae are rotated according to the prescribed angles.

The accuracy of the computed natural frequencies are shown in Table 2 for $\mathrm{CA}$ and in Table 3 for CB with trajectory defined as per Fig. 4. Also, Figure 3 portrays the modal assurance criteria (MAC) values for both configurations, where is shown the good match between the modes shapes obtained from NASTRAN and the counterparts obtained from the R.R. proposed model.

As per Table 2 and Table 3 considering six assumed modes in both $x$ and $y$ directions is sufficient to guarantee the model convergence with an acceptable error. Also, the steered configuration for the developed R.-R. model and Nastran FE model are depicted in Fig. 4.

\section{Optimization Procedure}

The Differential Evolution (DE) algorithm is used to achieve the maximum aeroelastic instability margin of non steered and steered plates subjected to aerodynamic load. In addition, the optimization procedure was done considering suitable generations and populations, evaluating at least five tests for each configuration.

Five different optimizations are proposed, as presented in Fig. 5. The first optimization (O1) considers only non-steered trajectory and discrete conventional angles $\left( \pm 45^{0}, 0^{0}, 90^{0}\right)$. The second optimization considers also a non-steered plate $(\mathrm{O} 2)$, but the angles can vary continuously between $-90^{0}$ to $+90^{0}$. Then, in the third optimization (O3), the VSP has fiber paths defined by a first order Lagrange polynomial in both $\mathrm{x}$ and $\mathrm{y}$ direction. In the forth optimization (O4) the trajectories is defined by second order Lagrange polynomial. And, the last optimization (O5) a third order Lagrange polynomial is used to define steering angles.

In Table 4 is summarized the description of each optimization, the design variables and their types, and their lateral constraints. Therefore, the optimization problem can be stated as: 

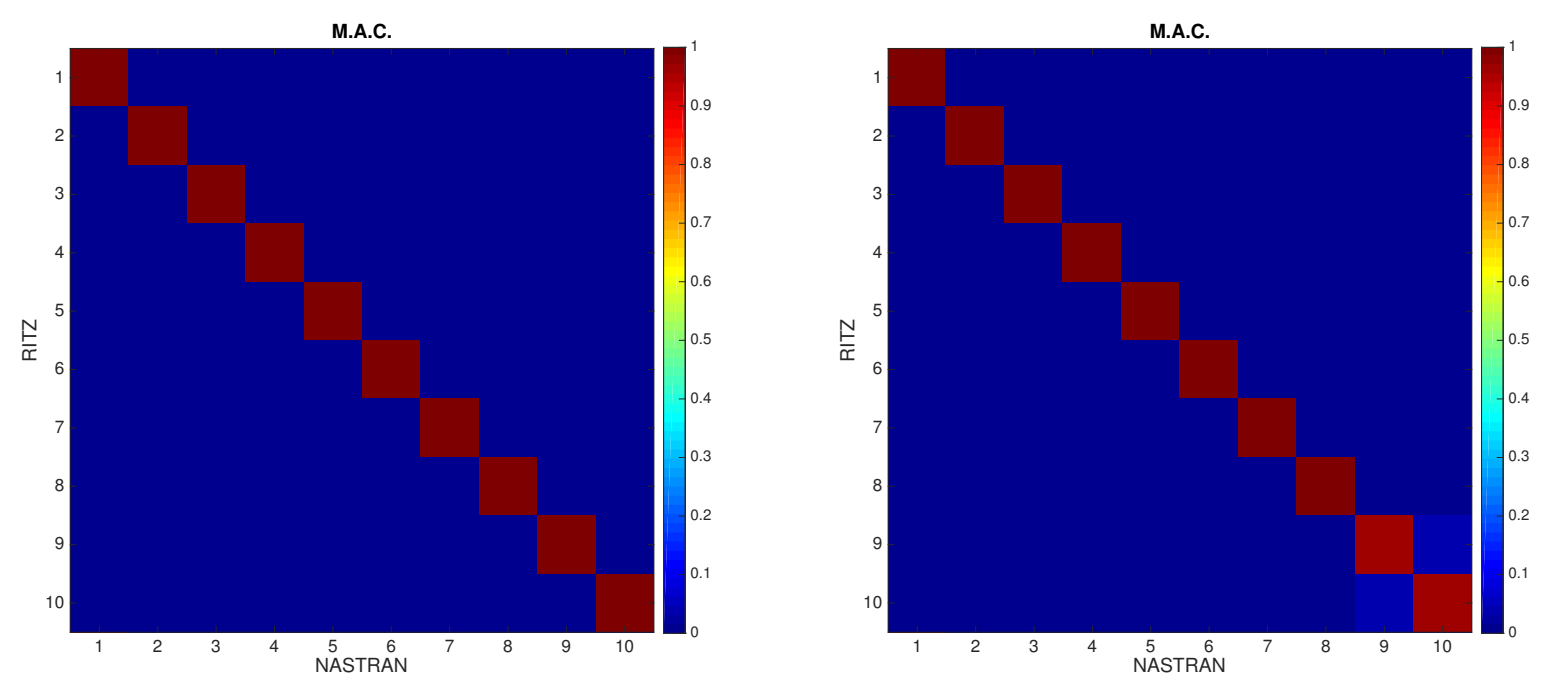

Figure 3. Mode Assurance Criteria for CA and CB

Table 2. Comparison of the values of natural frequencies obtained by R.R. and the FE model for configuration A

\begin{tabular}{|c|c|c|c|c|c|c|c|}
\hline & & $\omega_{n 1}(\mathrm{~Hz})$ & $\omega_{n 2}(\mathrm{~Hz})$ & $\omega_{n 3}(\mathrm{~Hz})$ & $\omega_{n 4}(\mathrm{~Hz})$ & $\omega_{n 5}(\mathrm{~Hz})$ & $\omega_{n 6}(\mathrm{~Hz})$ \\
\hline & Nastran & 63.88 & 152.47 & 166.97 & 248.68 & 309.94 & 333.02 \\
\hline \multirow{16}{*}{ R.R. } & $m_{\max }=3, n_{\max }=3$ & 64.64 & 154.26 & 169.10 & 254.81 & 315.60 & 337.37 \\
\hline & & $(1.18)$ & $(1.17)$ & $(1.27)$ & $(2.46)$ & $(1.82)$ & $(1.30)$ \\
\hline & $m_{\max }=4, n_{\max }=4$ & 64.53 & 154.20 & 168.93 & 254.63 & 313.88 & 336.64 \\
\hline & & $(1.01)$ & $(1.13)$ & $(1.17)$ & $(2.39)$ & $(1.27)$ & $(1.08)$ \\
\hline & $m_{\max }=5, n_{\max }=5$ & 64.52 & 154.06 & 168.88 & 254.20 & 313.80 & 336.62 \\
\hline & & $(1.00)$ & $(1.04)$ & $(1.14)$ & $(2.21)$ & $(1.24)$ & $(1.08)$ \\
\hline & $m_{\max }=6, n_{\max }=6$ & 64.48 & 154.05 & 168.81 & 254.16 & 313.62 & 336.51 \\
\hline & & $(0.93)$ & $(1.03)$ & $(1.10)$ & $(2.20)$ & $(1.18)$ & $(1.04)$ \\
\hline & $m_{\max }=7, n_{\max }=7$ & 64.48 & 153.99 & 168.79 & 254.00 & 313.59 & 336.50 \\
\hline & & $(0.93)$ & $(0.99)$ & $(1.09)$ & $(2.13)$ & $(1.17)$ & $(1.04)$ \\
\hline & $m_{\max }=8, n_{\max }=8$ & 64.45 & 153.98 & 168.76 & 253.98 & 313.52 & 336.45 \\
\hline & & $(0.89)$ & $(0.99)$ & $(1.07)$ & $(2.13)$ & $(1.15)$ & $(1.03)$ \\
\hline & $m_{\max }=9, n_{\max }=9$ & 64.45 & 153.95 & 168.75 & 253.90 & 313.50 & 336.45 \\
\hline & & $(0.89)$ & $(0.97)$ & $(1.06)$ & $(2.09)$ & $(1.14)$ & $(1.03)$ \\
\hline & $m_{\max }=10, n_{\max }=10$ & 64.45 & 153.95 & 168.75 & 253.90 & 313.50 & 336.45 \\
\hline & & $(0.86)$ & $(0.97)$ & $(1.04)$ & $(2.09)$ & $(1.13)$ & $(1.01)$ \\
\hline
\end{tabular}

* Values indicated between parentheses are relatives deviations

\section{Maximize: $\lambda_{\text {flutter }}$}

Design Variables: As per second column of Table 4

Subject to: As per forth column of Table 4

It is proposed to use the results from $\mathrm{O} 1$ as baseline layup for O3, O4 and $\mathrm{O} 5$. 
Table 3. Comparison of the values of natural frequencies obtained by R.R. and the FE model for configuration B

\begin{tabular}{|c|c|c|c|c|c|c|c|}
\hline & & $\omega_{n 1}(\mathrm{~Hz})$ & $\omega_{n 2}(\mathrm{~Hz})$ & $\omega_{n 3}(\mathrm{~Hz})$ & $\omega_{n 4}(\mathrm{~Hz})$ & $\omega_{n 5}(\mathrm{~Hz})$ & $\omega_{n 6}(\mathrm{~Hz})$ \\
\hline & Nastran & 65.38 & 151.55 & 170.43 & 248.68 & 319.74 & 330.67 \\
\hline \multirow{8}{*}{ R.R. } & $m_{\max }=3, n_{\max }=3$ & $\begin{array}{l}66.03 \\
(0.99)\end{array}$ & $\begin{array}{l}153.29 \\
(1.15)\end{array}$ & $\begin{array}{l}172.80 \\
(1.39)\end{array}$ & $\begin{array}{l}252.79 \\
(1.65)\end{array}$ & $\begin{array}{l}326.56 \\
(2.13)\end{array}$ & $\begin{array}{l}337.03 \\
(1.92)\end{array}$ \\
\hline & $m_{\max }=4, n_{\max }=4$ & $\begin{array}{l}66.00 \\
(0.95)\end{array}$ & $\begin{array}{l}153.03 \\
(0.98)\end{array}$ & $\begin{array}{l}172.49 \\
(1.21)\end{array}$ & $\begin{array}{l}252.26 \\
(1.44)\end{array}$ & $\begin{array}{l}324.34 \\
(1.44)\end{array}$ & $\begin{array}{l}335.19 \\
(1.37)\end{array}$ \\
\hline & $m_{\max }=5, n_{\max }=5$ & $\begin{array}{l}66.00 \\
(0.95) \\
\end{array}$ & $\begin{array}{l}153.01 \\
(0.96) \\
\end{array}$ & $\begin{array}{l}172.47 \\
(1.20) \\
\end{array}$ & $\begin{array}{l}252.11 \\
(1.38) \\
\end{array}$ & $\begin{array}{l}323.34 \\
(1.13) \\
\end{array}$ & $\begin{array}{l}334.79 \\
(1.25) \\
\end{array}$ \\
\hline & $m_{\max }=6, n_{\max }=6$ & $\begin{array}{l}65.97 \\
(0.90) \\
\end{array}$ & $\begin{array}{l}152.98 \\
(0.94) \\
\end{array}$ & $\begin{array}{l}172.43 \\
(1.17) \\
\end{array}$ & $\begin{array}{l}252.08 \\
(1.37) \\
\end{array}$ & $\begin{array}{l}323.31 \\
(1.12) \\
\end{array}$ & $\begin{array}{l}334.69 \\
(1.22) \\
\end{array}$ \\
\hline & $m_{\max }=7, n_{\max }=7$ & $\begin{array}{l}65.97 \\
(0.90)\end{array}$ & $\begin{array}{l}152.95 \\
(0.92)\end{array}$ & $\begin{array}{l}172.41 \\
(1.16)\end{array}$ & $\begin{array}{l}251.96 \\
(1.32)\end{array}$ & $\begin{array}{l}323.30 \\
(1.11)\end{array}$ & $\begin{array}{l}334.68 \\
(1.21)\end{array}$ \\
\hline & $m_{\max }=8, n_{\max }=8$ & $\begin{array}{l}65.96 \\
(0.89) \\
\end{array}$ & $\begin{array}{l}152.94 \\
(0.92) \\
\end{array}$ & $\begin{array}{l}172.39 \\
(1.15) \\
\end{array}$ & $\begin{array}{l}251.94 \\
(1.31) \\
\end{array}$ & $\begin{array}{l}323.25 \\
(1.10) \\
\end{array}$ & $\begin{array}{l}334.64 \\
(1.20) \\
\end{array}$ \\
\hline & $m_{\max }=9, n_{\max }=9$ & $\begin{array}{l}65.96 \\
(0.89) \\
\end{array}$ & $\begin{array}{l}152.92 \\
(0.90) \\
\end{array}$ & $\begin{array}{l}172.38 \\
(1.14) \\
\end{array}$ & $\begin{array}{l}251.87 \\
(1.28) \\
\end{array}$ & $\begin{array}{l}323.24 \\
(1.09) \\
\end{array}$ & $\begin{array}{l}334.64 \\
(1.20) \\
\end{array}$ \\
\hline & $m_{\max }=10, n_{\max }=10$ & $\begin{array}{l}65.95 \\
(0.87)\end{array}$ & $\begin{array}{l}152.91 \\
(0.90)\end{array}$ & $\begin{array}{l}172.37 \\
(1.14)\end{array}$ & $\begin{array}{l}251.86 \\
(1.28)\end{array}$ & $\begin{array}{l}323.21 \\
(1.09)\end{array}$ & $\begin{array}{l}334.62 \\
(1.19)\end{array}$ \\
\hline
\end{tabular}

* Values indicated between parentheses are relatives deviations

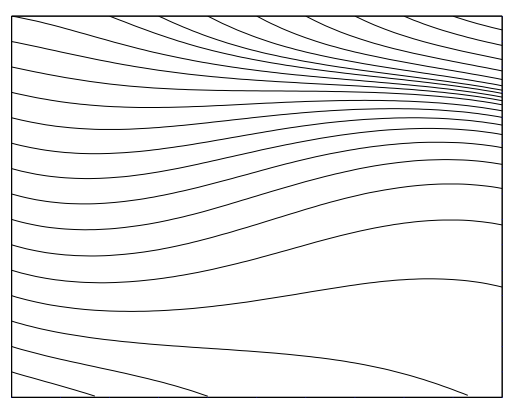

(a)

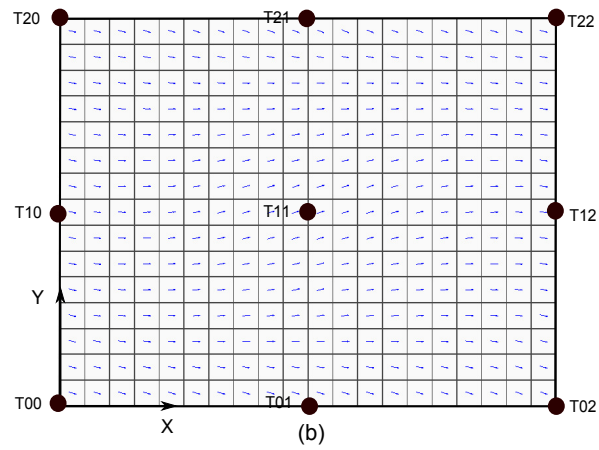

Figure 4. Steering Lamina - a) Rayleigh-Ritz model; b) Nastran Model

\section{A. Manufacturing Constraints}

In the current stage of manufacturing technology, the realization of tow steered composites is limited due the fact that the trajectories of small curvature radius are associated to larger densities of defects (gaps and overlaps). In this sense, the best strategy found in the literature to tackle this limitations is the fiber placement using constant curvature courses ${ }^{16}$ because programming of the placement machine is easier and the induced defects can be controlled in terms of the turning radius.

The tow steered path is formulated using three different parameters $\left(\Phi, T_{0}\right.$ and $\left.T_{1}\right)$. The turning radius, is determined by: ${ }^{26}$

$$
r=\frac{a}{\sin T_{1}-\sin T_{0}}
$$

is the most relevant manufacturing constraint that should be taken into account to avoid local buckling, wrinkle out of the plane and crimping during fiber placement, which are prone to reduce the strength of laminate. Considering a typical ply width $(3.17 \mathrm{~mm})$ the minimum turning radius allowable is found to be 


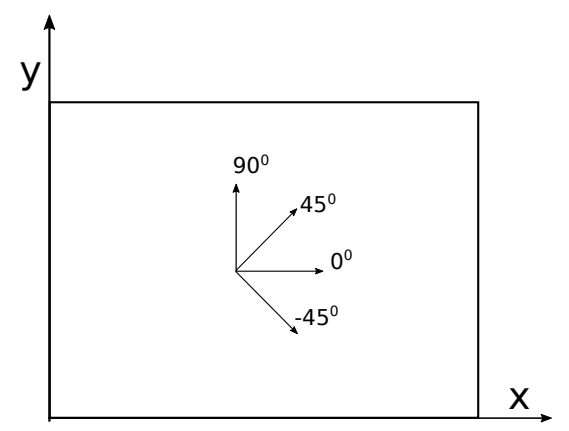

O1 - Non sterred

4 variables $\left(\theta_{1}, \theta_{2}, \theta_{3}, \theta_{4}\right)$

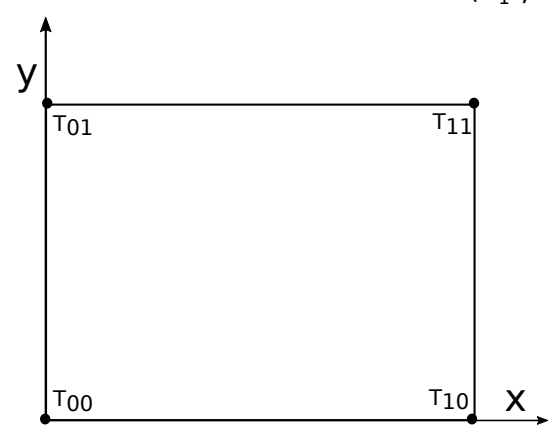

O3 $-1^{\text {st }}$ order

4 variables $\left(T_{00}, T_{01}, T_{10}, T_{11}\right)$

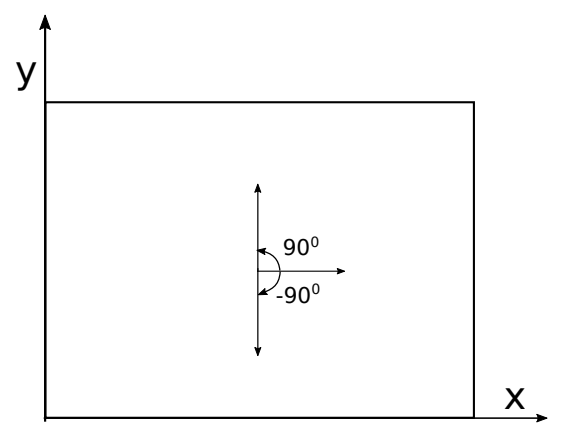

O2 - Non steered

4 variables $\left(\theta_{1}, \theta_{2}, \theta_{3}, \theta_{4}\right)$

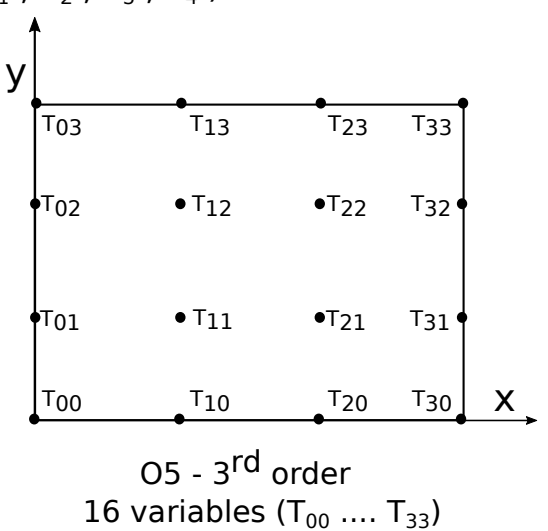

Figure 5. Configurations adopted for optimization and their types

Table 4. Lay-up options and design variables

\begin{tabular}{|c|c|c|c|}
\hline Configuration & Design Variables & Variables Type & Boundaries \\
\hline O1 & $\left.\begin{array}{cccc}\theta_{1} & \theta_{2} & \theta_{3} & \theta_{4}\end{array}\right]$ & Discrete & {$\left[\begin{array}{lll} \pm 45^{0} & 0^{0} & 90^{0}\end{array}\right]_{i}$} \\
\hline $\mathrm{O} 2$ & {$\left[\begin{array}{llll}\theta_{1} & \theta_{2} & \theta_{3} & \theta_{4}\end{array}\right]$} & Continuous & {$\left[\begin{array}{ll}-90^{0} & 90^{0}\end{array}\right]_{i}$} \\
\hline O3 & $\left.\begin{array}{ll}T_{01} & T_{11} \\
T_{00} & T_{10}\end{array}\right]$ & Continuous & {$\left[\begin{array}{ll}-90^{0} & 90^{0}\end{array}\right]_{i}$} \\
\hline $\mathrm{O} 4$ & $\begin{array}{lll}T_{02} & T_{12} & T_{22} \\
T_{01} & T_{11} & T_{21}\end{array}$ & Continuous & {$\left[\begin{array}{ll}-90^{0} & 90^{0}\end{array}\right]_{i}$} \\
\hline O5 & {$\left[\begin{array}{llll}I_{00} & 1_{10} & 1_{20} & ] \\
T_{03} & T_{13} & T_{23} & T_{33} \\
T_{02} & T_{12} & T_{22} & T_{32} \\
T_{01} & T_{11} & T_{21} & T_{31} \\
T_{00} & T_{10} & T_{20} & T_{30}\end{array}\right.$} & Continuous & {$\left[\begin{array}{ll}-90^{0} & 90^{0}\end{array}\right]_{i}$} \\
\hline
\end{tabular}

\section{$635 \mathrm{~mm}$.}

The steering angle in the ply is defined as:

$$
\sin (\theta(x))=\sin T_{0}+\left(\sin T_{1}-\sin T_{0}\right) \frac{x}{a}
$$

Consequently, considering a generic configuration where $T_{1}$ is different from $T_{0}$, the fiber trajectory is 
easily evaluated by integration of $d y / d x=\tan \theta(x)$ :

$$
y(x)=\int \tan (\theta(x)) d x=\frac{a \sqrt{1-\left(\sin \left(\mathrm{T}_{0}\right)-\frac{x\left(\sin \left(\mathrm{T}_{0}\right)-\sin \left(\mathrm{T}_{1}\right)\right)}{a}\right)^{2}}}{\sin \left(\mathrm{T}_{0}\right)-\sin \left(\mathrm{T}_{1}\right)}
$$

\section{Analysis and Results}

This section presents the results of flutter analysis and optimization for five different configurations of composite plates, based on the procedures described in the previous sections.

Table 5 shows the characteristics of the optimized laminates, while Fig. 6 illustrates the obtained fiber trajectories for configurations $\mathrm{O} 3, \mathrm{O} 4$ e $\mathrm{O} 5$.

It can be seen that as the order of the polynomial describing the fiber placement trajectories increases, more complex shapes of deposition paths are obtained, which, in practical cases, can be infeasible due to manufacturing constraints.

It can also be seen that, taking $\mathrm{O} 1$ as a reference, all optimized configurations provided improvements of the flutter speed. This improvement increases with the order of the polynomial used to described the fiber trajectories.

Figure 7 illustrates the evolution of the eigenvalues of the aeroelastic system, (showing the coalescence of natural frequencies that characterizes the onset of instability), for the optimized configurations.

Table 5. Optimization Results

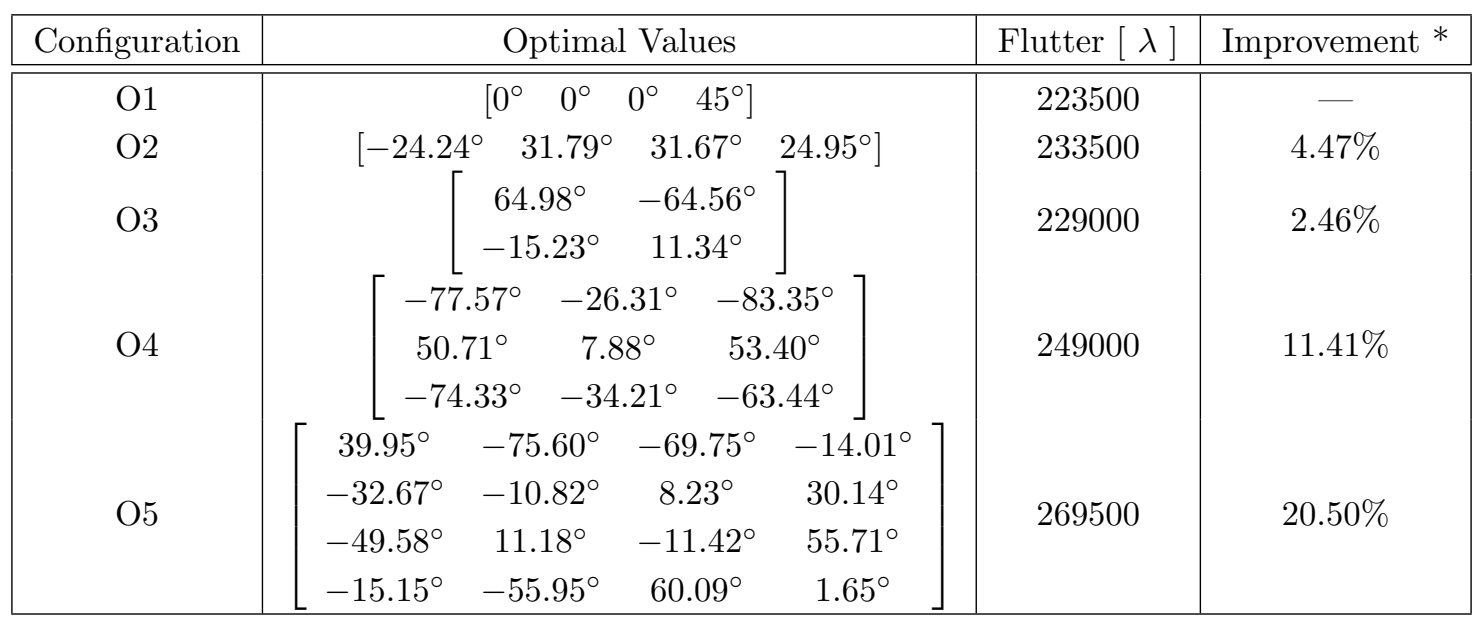

* Improvements of flutter speed with respect to configuration O1.

O3

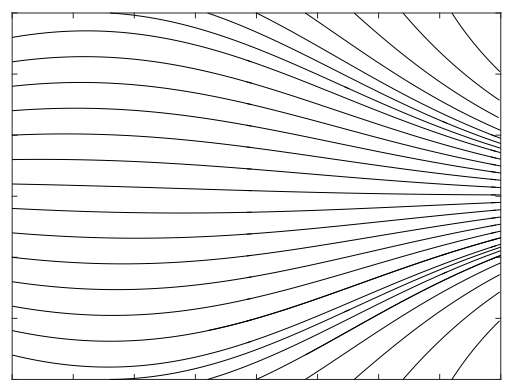

04

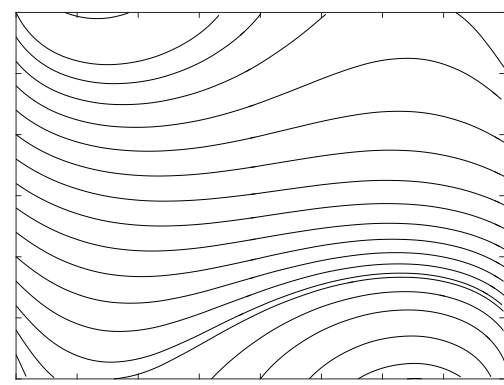

05

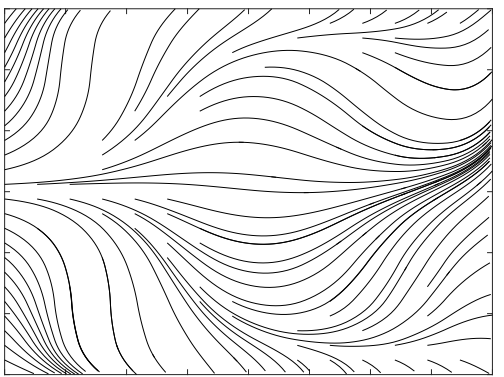

Figure 6. Optimized Trajectories for configurations O3, O4 e O5

Also, the results obtained for the problem combining aeroelastic and buckling stability (according to Eq. 29), are shown in Fig. 8. It can be seen that O3, O4 e O5 have quite similar buckling loads, but the non-steered configuration optimized with continuous $\mathrm{O} 2$ presents best results in terms of buckling load. 


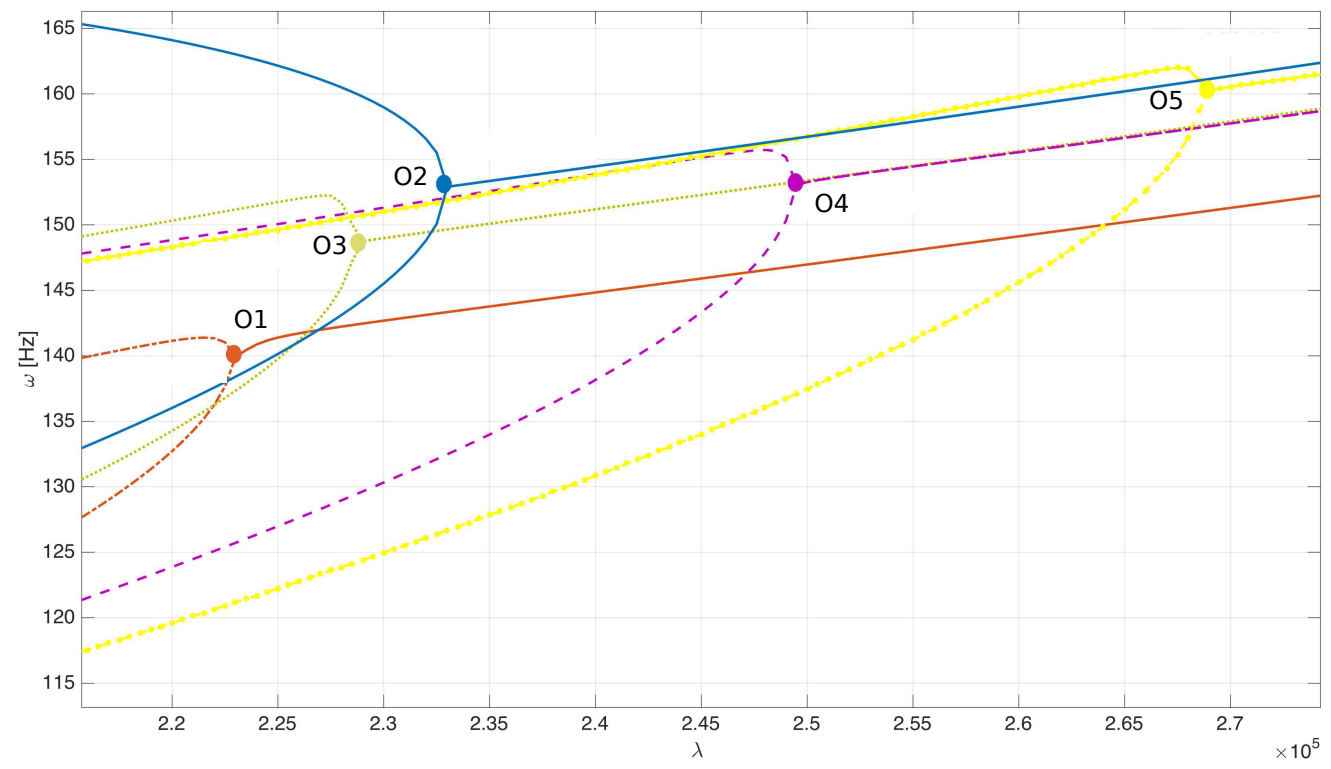

Figure 7. Aeroelastic Evaluation - Evolution of the natural frequency for the optimized configurations

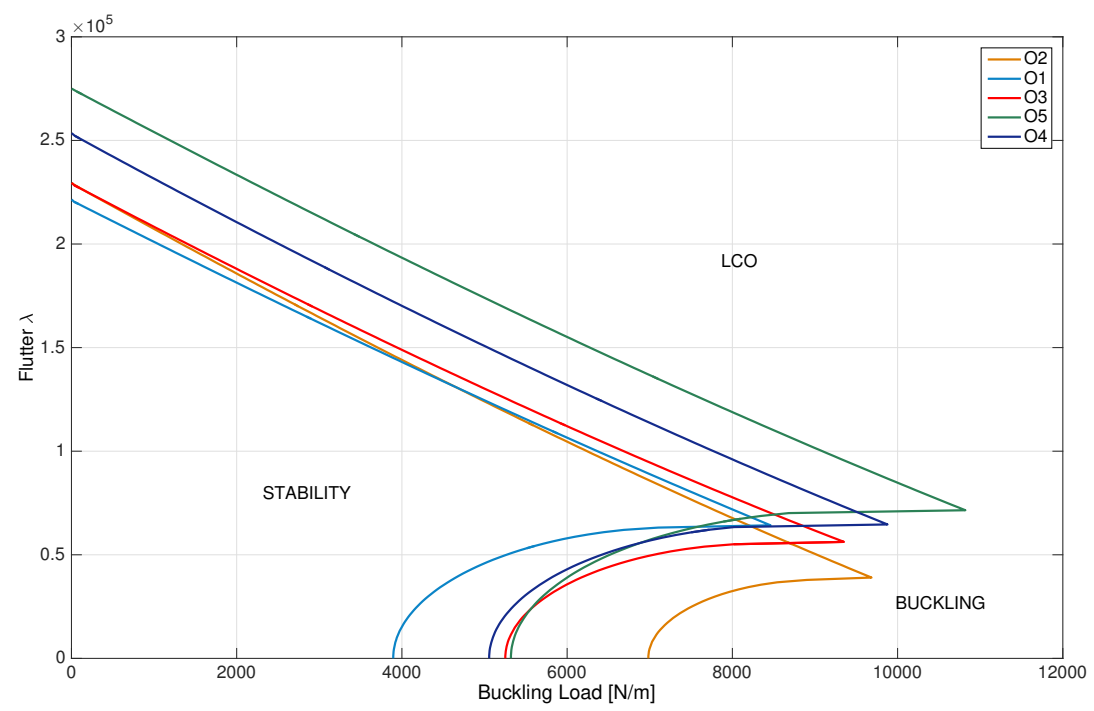

Figure 8. Buckling and Aeroelastic Evaluation - Flutter Results Comparison

\section{A. Flutter and Buckling optimization under manufacturing constraints}

A multi-objective optimization was done considering six different variables, composed of the tow steered an-

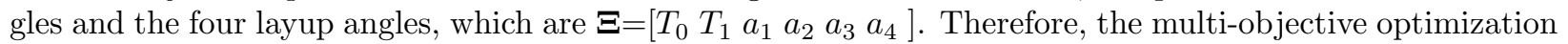
problem is stated as:

$$
\text { Maximize: } \begin{aligned}
\mathcal{J}_{1}(\boldsymbol{\Xi}) & =\text { flutter }(\boldsymbol{\Xi},) \\
& \mathcal{J}_{2}(\boldsymbol{\Xi})=\operatorname{buckling} \operatorname{load}(\boldsymbol{\Xi},)
\end{aligned}
$$

subject to: (min. bound value $)_{i} \leq(\boldsymbol{\Xi})_{i} \leq(\max \text {. bound value })_{i}$;

The results shown in Fig. 8 lead to conclude that the requirements for flutter and buckling stability can be conflicting with each other. Therefore, the possibility of increasing the combined stability region 
in the $\alpha \lambda$ plane by a multi-objective criteria optimization approach was investigated, accounting for the manufacturing constraints addressed in subsection VI A.

The fiber placement trajectory follows constant-curvature courses and the manufacturing constraints obey the rule of minimum turning radius, as given by Eq. 32. The influence of the manufacturing constraints can be evaluated in Fig. 9, which shows the Pareto fronts obtained from optimization runs in two different conditions: accounting for manufacturing constraints and not accounting for this constraint.

Comparing performance of configuration OM with the baseline non-steered configuration O1, it can be seen that the aeroelastic-buckling behavior of OM is noticeably superior of that of O1. The stability region for $\mathrm{OM}$ is much broader then that for $\mathrm{O} 1$; the buckling load for OM is more than double the counterpart for $\mathrm{O} 1$.

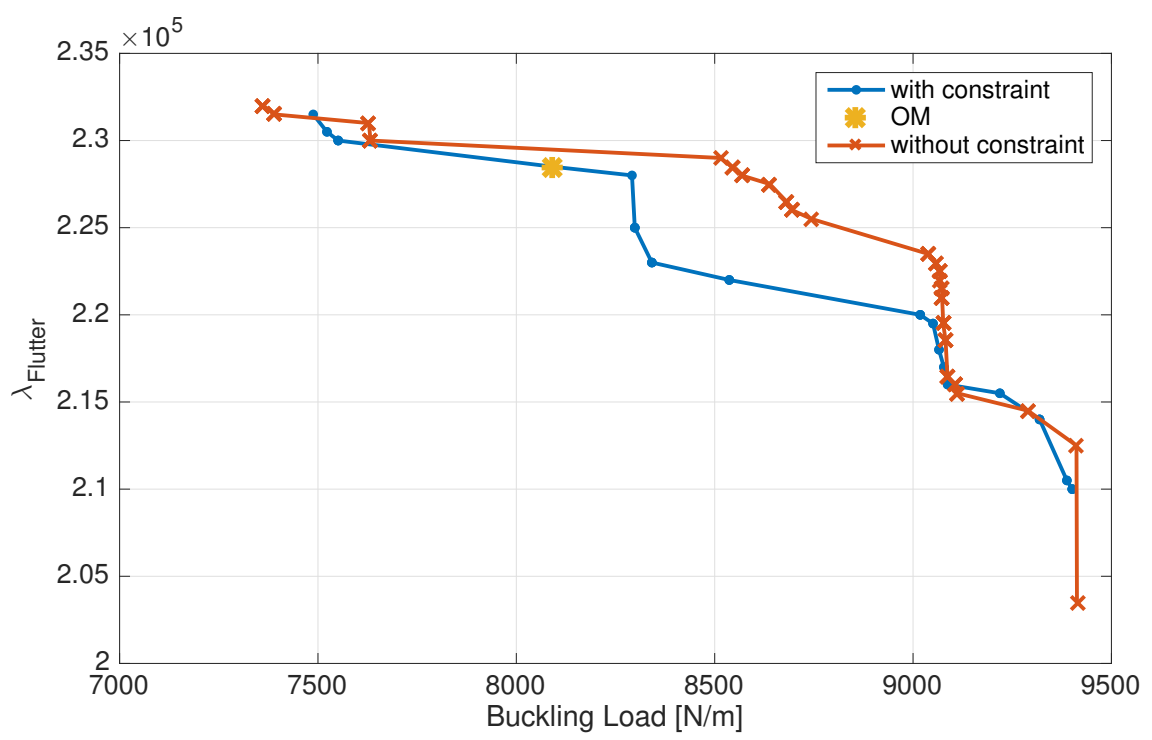

Figure 9. Pareto fronts obtained from two multi-criteria optimization runs.

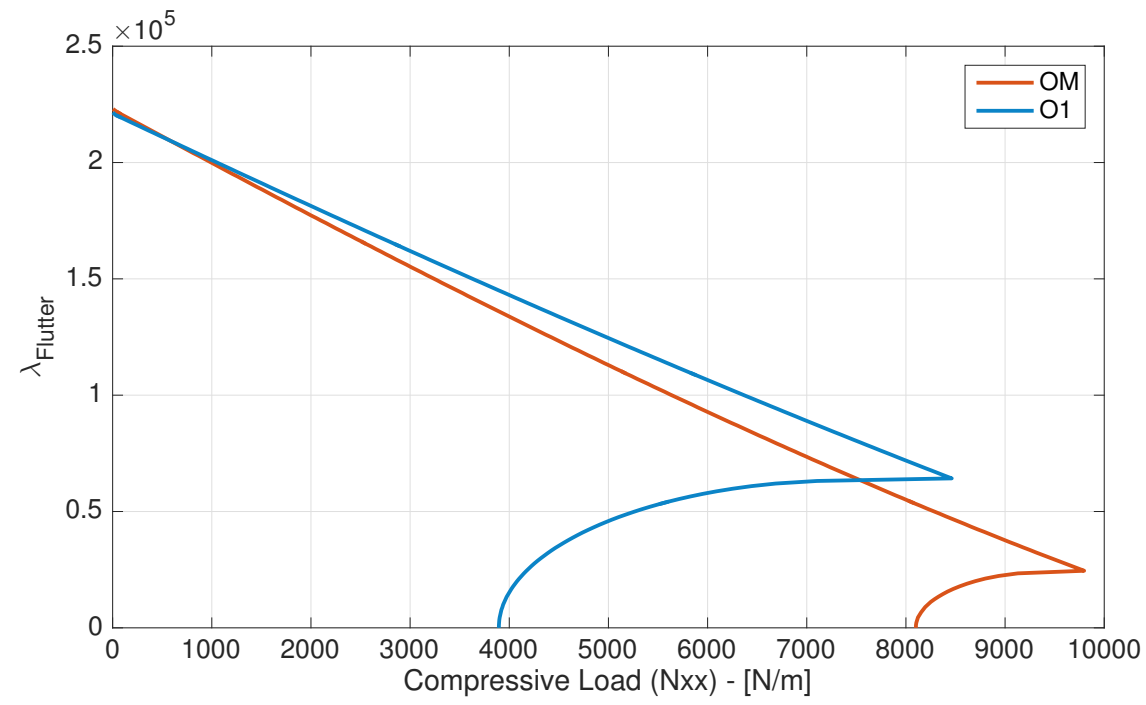

Figure 10. Aero-buckling behavior comparison 


\section{Summary and Conclusion}

The theoretical modeling and numerical investigation of variable stiffness composite plates were presented in this paper. The linear and geometrically non linear formulation were developed based on Rayleigh-Ritz approach, in combination with the use of Lagrange polynomials of various orders to represent the fiber deposition path over each lamina. The formulation includes the statement of eigenvalue problems associated to dynamic stability (flutter), linear buckling and combination of these two types.

In the numerical simulations, it was attempted to compare the instability behavior of VSP with traditional unidirectional fiber deposition counterparts in order to evaluate the possible benefits provided by tow steering. Such benefits have been quantified, thus corroborating the findings reported in previous studies.

Single objective and multi-objective problems have been formulated and solved numerically for the purpose of maximizing the stability behavior. In particular, constraints imposed by manufacturing restrictions have been accounted for.

The optimization tests were found to be successful in determining steered configurations with improved buckling and flutter behaviors, as compared to traditional non-steered laminate composites.

\section{ACKNOWLEDGMENTS}

The authors are thankful to Brazilian Research Agencies CNPq (Projects 310633/2013-3 and 402238/20133), CAPES, FAPEMIG, FAPESP and the INCT-EIE for the continuous support to their research work.

\section{References}

${ }^{1}$ Dowell, E., "Nonlinear oscillations of a fluttering plate." AIAA Journal, Vol. 4, No. 7, July 1966, pp. 1267-1275.

$>2$ Dowell, E., "Panel flutter - A review of the aeroelastic stability of plates and shells," AIAA Journal, Vol. 8, No. 3, March 1970, pp. 385-399.

${ }^{3}$ Yang, T. Y. and SUNG, S. H., "Finite-element panel flutter in three-dimensional supersonic unsteady potential flow," AIAA Journal, Vol. 15, No. 12, Dec. 1977, pp. 1677-1683.

${ }^{4}$ Xue, D. Y. and MEI, C., "Finite element nonlinear panel flutter with arbitrary temperatures in supersonic flow," AIAA Journal, Vol. 31, No. 1, Jan. 1993, pp. 154-162.

${ }^{5}$ Shore, C. P., MEI, C., and GRAY, C. E., "Finite element method for large-amplitude two-dimensional panel flutter at hypersonic speeds," AIAA Journal, Vol. 29, No. 2, Feb. 1991, pp. 290-298.

${ }^{6}$ Zhou, R. C., Lai, Z., Xue, D. Y., Huang, J.-K., and Mei, C., "Suppression of nonlinear panel flutter with piezoelectric actuators using finite element method," AIAA Journal, Vol. 33, No. 6, 2016/09/16 1995, pp. 1098-1105.

${ }^{7}$ Castro, S. G. P., Guimarães, T. A. M., Rade, D. A., and Donadon, M. V., "Flutter of stiffened composite panels considering the stiffener's base as a structural element," Composite Structures, Vol. 140, 4 2016, pp. 36-43.

${ }^{8}$ Hasheminejad, S. M. and Aghayi Motaaleghi, M., "Aeroelastic analysis and active flutter suppression of an electrorheological sandwich cylindrical panel under yawed supersonic flow," Aerospace Science and Technology, Vol. 42, 2015/5// 2015, pp. 118-127.

${ }^{9}$ Shirk, M. H., Hertz, T. J., and Weisshaar, T. A., "Aeroelastic tailoring - Theory, practice, and promise," Journal of Aircraft, Vol. 23, No. 1, Jan. 1986, pp. 6-18.

$\checkmark{ }^{10}$ Lopes, C., Gürdal, Z., and Camanho, P., "Variable-stiffness composite panels: Buckling and first-ply failure improvements over straight-fibre laminates," Computers and Structures, Vol. 86, No. 9, 2008, pp. 897 - 907, Composites.

${ }^{11}$ Hyer, M. W. and Charette, R. F., "Use of curvilinear fiber format in composite structure design," AIAA Journal, Vol. 29, No. 6, June 1991, pp. 1011-1015.

${ }^{12}$ Akhavan, H. and Ribeiro, P., "Natural modes of vibration of variable stiffness composite laminates with curvilinear fibers," Composite Structures, Vol. 93, No. 11, 2011, pp. 3040 - 3047.

${ }^{13}$ Stodieck, O., Cooper, J. E., Weaver, P. M., and Kealy, P., "Improved aeroelastic tailoring using tow-steered composites," Composite Structures, Vol. 106, Dec. 2013, pp. 703-715.

$\checkmark{ }^{14}$ Stanford, B. K., Jutte, C. V., and Chauncey Wu, K., "Aeroelastic benefits of tow steering for composite plates," Composite Structures, Vol. 118, Dec. 2014, pp. 416-422.

${ }^{15}$ Akbarzadeh, A. H., Arian Nik, M., and Pasini, D., "The role of shear deformation in laminated plates with curvilinear fiber paths and embedded defects," Composite Structures, Vol. 118, 12 2014, pp. 217-227.

16 Fayazbakhsh, K., Arian Nik, M., Pasini, D., and Lessard, L., "Defect layer method to capture effect of gaps and overlaps in variable stiffness laminates made by Automated Fiber Placement," Composite Structures, Vol. 97, 3 2013, pp. $245-251$.

${ }^{17}$ Akbarzadeh, A. H., Arian Nik, M., and Pasini, D., "Vibration responses and suppression of variable stiffness laminates with optimally steered fibers and magnetostrictive layers," Composites Part B: Engineering, Vol. 91, 4 2016, pp. 315-326.

${ }^{18} \mathrm{Wu}, \mathrm{Z}$., Weaver, P. M., Raju, G., and Chul Kim, B., "Buckling analysis and optimisation of variable angle tow composite plates," Thin-Walled Structures, Vol. 60, 11 2012, pp. 163-172.

${ }^{19}$ Ghiasi, H., Fayazbakhsh, K., Pasini, D., and Lessard, L., "Optimum stacking sequence design of composite materials Part II: Variable stiffness design," Composite Structures, Vol. 93, No. 1, 12 2010, pp. 1-13.

${ }^{20}$ Tsai, H., Introduction to composite materials, Lancaster: Technomic, 1980. 
${ }^{21}$ Jones, R., Mechanics of composite materials, CRC, 1998.

${ }^{22}$ Love, A. E. H., "The Small Free Vibrations and Deformation of a Thin Elastic Shell," Philosophical Transactions of the Royal Society of London A: Mathematical, Physical and Engineering Sciences, Vol. 179, 1888, pp. $491-546$.

${ }^{23}$ Amabili, M. and Pellicano, F., "Multimode Approach to Nonlinear Supersonic Flutter of Imperfect Circular Cylindrical Shells," Journal of Applied Mechanics, Vol. 69, No. 2, Oct. 2001, pp. 117-129.

${ }^{24}$ Lagrange, J. L., Mecanique Analytique:, Vol. 1, Cambridge University Press, Cambridge, 2009.

${ }^{25}$ Loughlan, J., "The buckling performance of composite stiffened panel structures subjected to combined in-plane compression and shear loading," Composite Structures, Vol. 29, No. 2, 1994, pp. $197-212$.

$\checkmark{ }^{26}$ Falcó, O., Mayugo, J. A., Lopes, C. S., Gascons, N., Turon, A., and Costa, J., "Variable-stiffness composite panels: Asmanufactured modeling and its influence on the failure behavior," Composites Part B: Engineering, Vol. 56, 12014 , pp. 660-669. 